\title{
Ultrasonographic features differentiating thyroglossal duct cysts from dermoid cysts
}

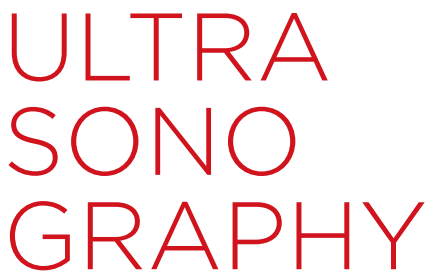

\author{
Hyoung In Choi ${ }^{1,2}$, Young Hun Choi ${ }^{1,2}$, Jung-Eun Cheon ${ }^{1,2,3}$, Woo Sun Kim ${ }^{1,2,3}$, \\ In-One Kim ${ }^{1,2,3}$ \\ ${ }^{1}$ Department of Radiology, Seoul National University Hospital, Seoul; ${ }^{2}$ Department of \\ Radiology, Seoul National University College of Medicine, Seoul; ${ }^{3}$ Institute of Radiation \\ Medicine, Seoul National University Medical Research Center, Seoul, Korea
}

\section{ORIGINAL ARTICLE}

https://doi.org/10.14366/usg. 17027 pISSN: 2288-5919 - eISSN: 2288-5943 Ultrasonography 2018;37:71-77

Received: March 14, 2017

Revised: May 19, 2017

Accepted: May 24, 2017

Correspondence to:

Young Hun Choi, MD, PhD, Department of Radiology, Seoul National University Hospital, Seoul National University College of Medicine, 101 Daehak-ro, Jongno-gu, Seoul 03080, Korea

Tel. $+82-2-2072-3608$

Fax. +82-2-747-5781

E-mail: iater@snu.ac.kr

This is an Open Access article distributed under the terms of the Creative Commons Attribution NonCommercial License (http://creativecommons.org/ licenses/by-n/3.0/) which permits unrestricted noncommercial use, distribution, and reproduction in any medium, provided the original work is properly cited.

Copyright (c) 2018 Korean Society of Ultrasound in Medicine (KSUM)

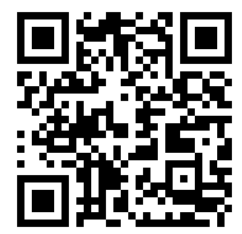

How to cite this article:

Choi HI, Choi YH, Cheon JE, Kim WS, Kim IO Ultrasonographic features differentiating thyroglossal duct cysts from dermoid cysts. Ultrasonography. 2018 Jan;37(1):71-77. 
[10].

Therefore, it is important that surgeons use imaging techniques to diagnose anterior neck cysts before surgery. A definitive diagnosis helps surgeons to obtain consent and plan surgery, and it limits the extent of surgery. Even though computed tomography or magnetic resonance imaging can be used for this purpose, ultrasonography (US) is the most commonly used initial imaging technique, because (1) it is easily accessible, (2) it does not involve radiation, and (3) it confers superior near-field resolution $[4,11,12]$. The US characteristics of TGDCs and DCs have been well described in several previous studies [4,12-14]. Nonetheless, few investigations have compared the US findings of TGDCs and DCs [15]. Therefore, the aim of this study was to identify ultrasonographic features that help differentiate between TGDCs and DCs in children who present with an anterior neck mass.

\section{Materials and Methods}

\section{Study Population}

Institutional review board approval was obtained for this retrospective study, and the requirement for informed consent was waived. We collected all confirmed cases of TGDC or DC by searching the pathology database at Seoul National University Hospital for reports completed between January 2004 and October 2015. Electronic medical records were also reviewed, and all patients were included if they were younger than 15 years of age when they presented with an anterior neck mass, had undergone surgery for-and were histologically confirmed as having-TGDC or DC, and had undergone preoperative US. Ultimately, 66 children (mean age, 4.18 years, range, 11 months to 15 years; 37 boys and 29 girls) were enrolled in our study.

\section{US Image Analysis}

All US examinations were performed using a high-frequency (5$12 \mathrm{MHz}$ ) linear probe; the patients were laid in the supine position, with neck extension. Serial transverse and longitudinal US images of the lesions were acquired, and color Doppler images were routinely obtained to evaluate internal vascularity. The US images were retrospectively reviewed by two radiologists who reached a consensus about the images (Y.H.C. and H.I.C.; 13 and 4 years' experience, respectively); both had been blinded to the pathology reports. The following sonographic findings were evaluated: (1) dimensions (length, width, and height) and volume, (2) shape (round/ ovoid vs. irregular), (3) margin (well-defined vs. ill-defined), (4) location in relation to the midline (midline vs. off-midline), (5) level in relation to the hyoid bone (suprahyoid, juxtahyoid, or infrahyoid), (6) attachment to the hyoid bone (present or absent), (7) depth of lesion in relation to the strap muscles (subcutaneous, intramuscular, or equivocal), (8) internal echogenicity (anechoic, homogeneous hypoechoic, homogeneous hyperechoic, or heterogeneous), (9) internal echogenic dots (present or absent), (10) multilocularity (unilocular vs. multilocular), (11) presence of a longitudinal extension into the tongue base, (12) posterior acoustic enhancement, (13) internal septae (present or absent), and (14) intralesional vascularity (present or absent). Volume was calculated using the following equation: volume $=(\pi / 6) \times$ length $\mathrm{x}$ height $\mathrm{x}$ width. If the lower margin of the mass was above the midline of the hyoid bone, it was defined as a suprahyoid mass. Conversely, if the upper margin of the mass was below the midline of the hyoid bone, it was defined as an infrahyoid mass. The attachment to the hyoid bone, on the other hand, was determined by whether the mass abutted the hyoid bone. The depth of the mass was classified as superficial when it was superficial and deep when it was deeper than the strap muscles. If the mass was neither superficial nor deep, it was called equivocal. The level of internal echogenicity was determined by comparison with that of the adjacent muscle. Echogenic dots were defined as brightly echogenic if they were similar to the adjacent hyoid bone, with a size of less than $1 \mathrm{~mm}$. Even if the mass was heterogeneous, the presence of internal echogenic dots was not difficult to distinguish. The presence of internal septae and multilocularity were defined based on the outer margin of the mass. Internal septae represent a thin linear echogenic structure within a round or oval mass with a smooth outer margin, and multilocularity refers to masses where the outer margin exhibits lobulation.

\section{Statistics}

Statistical analyses were performed using commercial software (SPSS ver. 22.0 for Windows, IBM Corp., Armonk, NY, USA). To compare US findings between TGDCs and DCs, the independent $t$ test was used for continuous variables, and the chi-square test or the Fisher exact test was used for categorical variables. P-values of $<0.05$ were considered to indicate statistical significance.

\section{Results}

Fifty children (mean age, 4.06 years; range, 11 months to 13 years; 32 boys and 18 girls) were diagnosed as having a TGDC, and 16 children (mean age, 4.56 years; range, 1 to 15 years; 5 boys and 11 girls) as having a DC. Age was not significantly different between the groups; however, there was a significant difference in terms of sex $(P=0.022)$, probably because of the small number of patients with DC. The demographic and US characteristics of each group are summarized in Table 1.

When the US findings were compared, the TGDC and DC groups 
Table 1. Demographic and ultrasound features of TGDCs and DCs

\begin{tabular}{|c|c|c|c|}
\hline Item & TGDC & DC & Significance (P-value) \\
\hline \multicolumn{4}{|l|}{ Sex } \\
\hline Male & 32 & 5 & $0.022^{*}$ \\
\hline Female & 18 & 11 & \\
\hline Age (yr) & $4.06 \pm 2.99$ & $4.56 \pm 3.84$ & 0.484 \\
\hline \multicolumn{4}{|l|}{ Ultrasound findings } \\
\hline Length (cm) & $1.56 \pm 0.52$ & $1.28 \pm 0.43$ & 0.052 \\
\hline Height (cm) & $0.95 \pm 0.40$ & $0.86 \pm 0.44$ & 0.441 \\
\hline Width (cm) & $1.64 \pm 0.66$ & $1.37 \pm 0.50$ & 0.131 \\
\hline Volume (mL) & $1.54 \pm 1.18$ & $1.40 \pm 1.18$ & 0.211 \\
\hline \multicolumn{4}{|l|}{ Shape } \\
\hline Round/Ovoid & $28(56.0)$ & $16(100)$ & $0.001^{*}$ \\
\hline Irregular & $22(44.0)$ & 0 & \\
\hline \multicolumn{4}{|l|}{ Margin } \\
\hline Well-defined & $38(76.0)$ & $16(100)$ & $0.030^{*}$ \\
\hline III-defined & $12(24.0)$ & 0 & \\
\hline \multicolumn{4}{|l|}{ Midline location } \\
\hline Midline & $33(66.0)$ & $9(56.2)$ & 0.480 \\
\hline Off-midline & $17(34.0)$ & $7(43.8)$ & \\
\hline \multicolumn{4}{|l|}{ Level in relation to the hyoid bone } \\
\hline Suprahyoid & $20(40.0)$ & $2(12.5)$ & 0.065 \\
\hline Juxtahyoid & $18(36.0)$ & $6(37.5)$ & \\
\hline Infrahyoid & $12(24.0)$ & $8(50.0)$ & \\
\hline \multicolumn{4}{|l|}{ Attachment to the hyoid bone } \\
\hline Present & $31(62.0)$ & $4(25.0)$ & $0.010^{*}$ \\
\hline Absent & $19(38.0)$ & $12(75.0)$ & \\
\hline \multicolumn{4}{|c|}{ Depth of lesion, in relation to strap muscles } \\
\hline Subcutaneous & $18(36.0)$ & $8(50.0)$ & $0.017^{*}$ \\
\hline Intramuscular & $25(50.0)$ & $2(12.5)$ & \\
\hline Equivocal & $7(14.0)$ & $6(37.5)$ & \\
\hline \multicolumn{4}{|l|}{ Internal echogenicity } \\
\hline Anechoic & $15(30.0)$ & 0 & $<0.001^{*}$ \\
\hline Homogeneous hypoechoic & $17(34.0)$ & $13(81.3)$ & \\
\hline Homogeneous hyperechoic & 0 & $2(12.5)$ & \\
\hline Heterogeneous & $18(36.0)$ & $1(6.3)$ & \\
\hline \multicolumn{4}{|l|}{ Internal echogenic dots } \\
\hline Present & $2(4.0)$ & $7(43.8)$ & $<0.001^{*}$ \\
\hline Absent & $48(96.0)$ & $9(56.2)$ & \\
\hline \multicolumn{4}{|l|}{ Multilocularity } \\
\hline Present & $12(24.0)$ & 0 & $0.030^{*}$ \\
\hline Absent & $38(76.0)$ & $16(100)$ & \\
\hline \multicolumn{4}{|c|}{ Presence of a longitudinal extension into the tongue base } \\
\hline Present & $12(24.0)$ & 0 & $0.030^{*}$ \\
\hline Absent & $38(76.0)$ & $16(100)$ & \\
\hline
\end{tabular}


Table 1. Continued

\begin{tabular}{lccc}
\hline \multicolumn{1}{c}{ Item } & TGDC & DC & Significance (P-value) \\
\hline Posterior acoustic enhancement & & & \\
Present & $27(54.0)$ & $13(81.2)$ & 0.052 \\
Absent & $23(46.0)$ & $3(18.8)$ & \\
Internal septae & & & 0.068 \\
$\quad$ Present & $9(18.0)$ & 0 & \\
Absent & $41(82.0)$ & $16(100)$ & 0.088 \\
Intralesional vascularity & & 0 & \\
Present & $8(16.0)$ & $16(100)$ & \\
Absent & $42(84.0)$ &
\end{tabular}

Values are presented as mean \pm standard deviation.

TGDC, thyroglossal duct cyst; DC, dermoid cyst.

*Significance was confirmed by P-values $<0.05$ on the basis of the independent $t$ test, chi-square test, or Fisher exact test.

were not significantly different in terms of dimensions or volume (volume, $1.54 \pm 1.18 \mathrm{~mL}$ vs. $1.40 \pm 1.18 \mathrm{~mL}$, respectively; $\mathrm{P}=0.211$ ).

All DCs had a round or oval shape, while 22 of the 50 TGDCs $(44 \%)$ showed an irregular outer contour $(\mathrm{P}<0.001)$. Similarly, all DCs were well-defined, while the margins of 12 TGDCs (24\%) were ill-defined ( $\mathrm{P}=0.030)$.

There were no significant differences between the groups in terms of midline location or level in relation to the hyoid bone. TGDCs were more often attached to the hyoid bone than DCs (TGDCs vs. $D C s, 62.0 \%$ vs. $25.0 \%$, respectively; $P=0.010$ ). The depth of the lesion also differed; TGDCs tended to be situated intramuscularly, while DCs were more likely to be located in the subcutaneous layer $(\mathrm{P}=0.017)$. Regarding internal echogenicity, TGDCs showed a variable appearance (anechoic, 30\%; homogeneously hypoechoic, $34 \%$; heterogeneous, $36 \%)$. On the contrary, 13 of the 16 DCs (81\%) were homogeneously hypoechoic. Internal echogenic dots were more frequent in DCs (TGDCs vs. DCs, $4 \%$ vs. $44 \%$, respectively; $P<0.01)$. TGDCs were multilocular in 12 patients $(24 \%)$, while all $D C s$ were unilocular $(P=0.030)$. TGDCs showed a longitudinal extension into the tongue base in 12 children (24\%), while such a finding was not observed in DCs ( $P=0.030)$. TGDCs did not differ significantly from DCs in terms of posterior acoustic enhancement, internal septae, or intralesional vascularity.

\section{Discussion}

TGDCs can develop anywhere along the line of embryological thyroid gland descent in the neck. The primitive thyroid starts to develop from a median outgrowth of the primitive pharynx floor, descends from the foramen cecum, penetrates through the underlying mesoderm of the tongue and floor of the mouth musculature, and eventually passes in an anterior direction towards the developing hyoid bone and laryngeal cartilages. It finally reaches the inferior part of the neck between the fourth and seventh weeks of embryological development. During its migration, the anlage of the thyroid gland is connected to the tongue by a narrow tubular structure, known as the TGD. This duct normally dissipates by the 10th gestational week; however, portions of this epithelial tract can remain and expand, leading to the formation of a $\operatorname{TGDC}[10,16,17]$. In contrast, DCs are developmental anomalies that occur within the squamous epithelium; they contain cheese-like, keratinaceous material and skin appendages (e.g., sebaceous glands and hair follicles). Approximately $7 \%$ of DCs occur in the head and neck, most commonly in the lateral eyebrow, followed by the floor of the mouth $[7,18,19]$.

Several studies have described the US findings of TGDCS and DCs $[5,12,13,20-22]$. Although some variability in terms of anechoic, homogeneously hypoechoic, and heterogeneous (complex) appearance has been reported [4], most TGDCs are thin-walled, unilocular, anechoic, midline neck masses; they tend to show posterior enhancement and are close to the hyoid bone $[12,13,20,21]$. In contrast, DCs are moderately thin-walled, unilocular masses located in the submandibular or sublingual space; they show a mixed internal echo and have a so-called pseudosolid appearance $[5-7,13,18,22]$. Our results were generally consistent with these previously reported features.

Even though TGDCs are usually described as thin-walled, unilocular, anechoic cystic masses (Fig. 1A), many of the TGDCs in the present study had an irregular shape (44.0\%), an ill-defined margin $(24.0 \%)$, heterogeneous internal echogenicity $(36.0 \%)$, or multilocular appearance $(24.0 \%)$, suggesting that TGDCs can have a complex appearance. Indeed, it is likely that the appearance of 


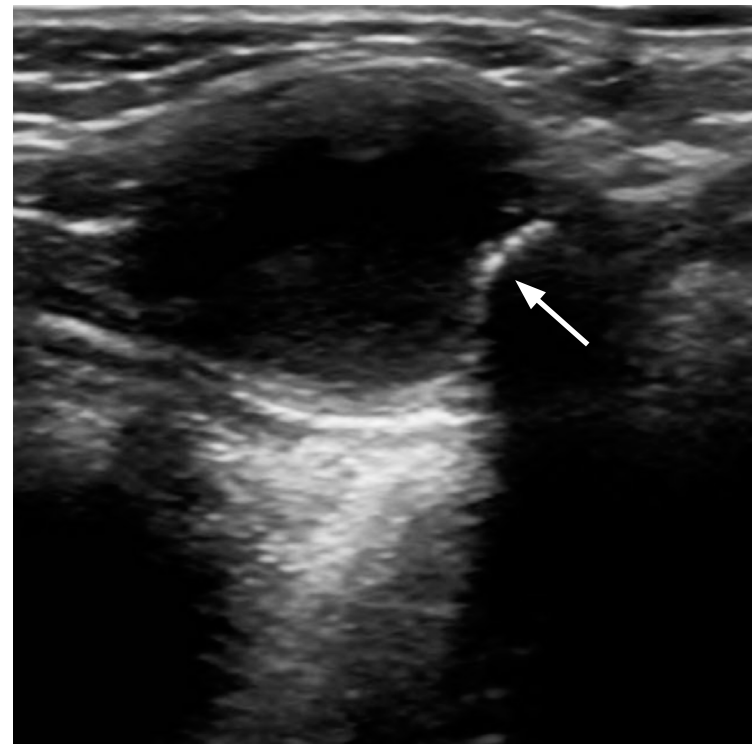

A

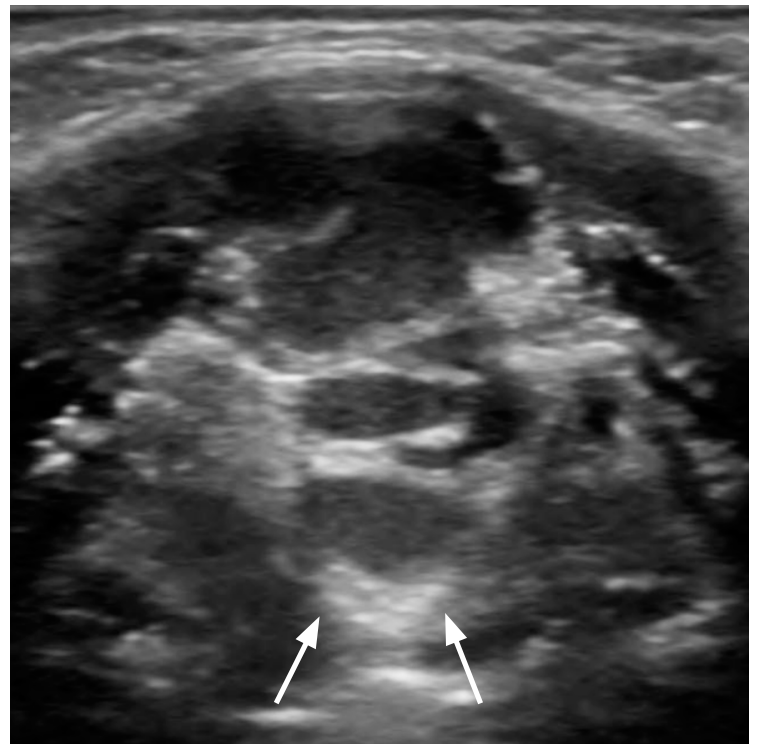

B

Fig. 1. A thyroglossal duct cyst in a 2-year-old boy (A) and a 3-year-old girl (B).

A. Longitudinal ultrasonography shows an oval, well-defined unilocular anechoic mass at the juxtahyoid level, with attachment to the hyoid bone (arrow) and posterior acoustic enhancement. B. Transverse ultrasonography shows an irregular, ill-defined, multilocular mass with longitudinal extension (arrows) into the tongue base.

TGDCs is related to the developmental complexity of the TGD or to the presence of infection or inflammation. However, no correlation has been reported between the US appearance and pathological evidence of infection and inflammation. Indeed, some authors have suggested that heterogeneous echogenicity is more likely due to proteinaceous content than infection $[4,22]$.

In this study, no significant differences were found between the groups in terms of diameter or volume. Both TGDCs and DCs had a mean maximal diameter of around $1.5 \mathrm{~cm}$, with the largest TGDC diameter being $3.4 \mathrm{~cm}$ and the largest DC diameter being $2.6 \mathrm{~cm}$. Similarly, there were no significant differences in terms of the mean volume, which was approximately $1.5 \mathrm{~mL}$. These findings support those of previous studies showing that the size of TGDCs and DCs is highly variable, and that the size changes with infection, location, and the duration of disease [18].

Neither midline location nor level in relation to the hyoid bone showed any significant difference between the TGDC and DC groups in the present study. Some authors have hypothesized that DCs typically occur along the midline because they result from the entrapment of epithelial elements in the TGD during development $[10,23]$.

As would be expected, given what is known about the normal development of the thyroid gland, the TGD is intimately associated with the developing hyoid bone, and TGDCs usually showed attachment to the hyoid bone in the present study (Fig. 1A).

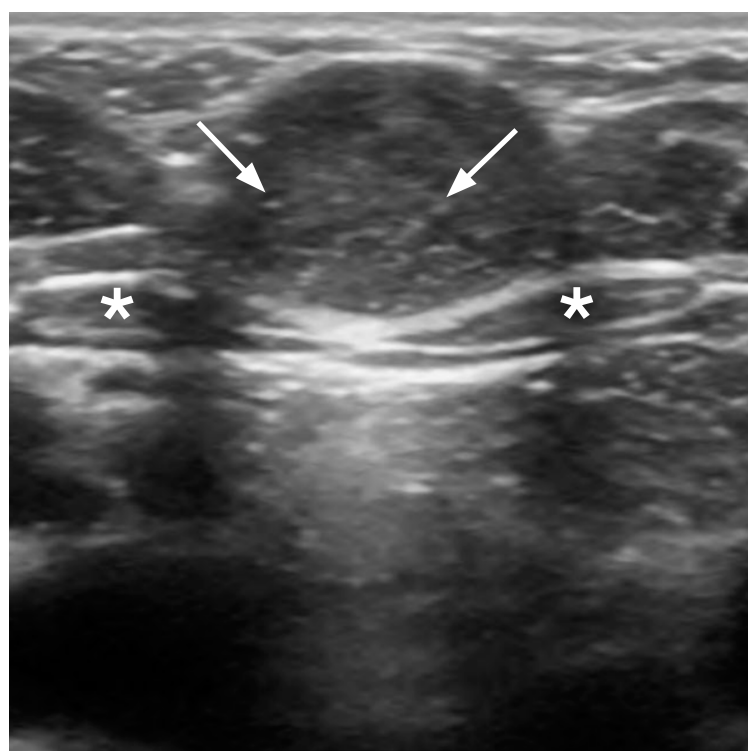

Fig. 2. Dermoid cyst in a 3-year-old girl. Transverse ultrasonography shows an oval, well-defined unilocular homogeneous hypoechoic mass with internal echogenic dots (arrows), superficial to the strap muscles (asterisks), showing posterior acoustic enhancement.

Likewise, only TGDCs showed longitudinal extensions into the tongue base (Fig. 1B). A previous study suggested that the presence of a tract of this type is associated with infected TGDCs [20]. Another study reported no difference in the clinical or pathological 
history of infection between patients with or without a tract, suggesting that tracts may not result solely from infection [15].

We also found that internal echogenic dots were more common in DCs (Fig. 2), perhaps because the lumen of DCs is filled with a mixture of keratin and sebaceous material, which may be reflective and cause echogenic dots on US. One previous report suggested that echogenic lesions in the cyst, which have the appearance of a "sack of marbles," are virtually pathognomic of DCs [22].

Interestingly, intralesional vascularity and internal septae were only present in TGDCs. In this regard, Oyewumi et al. [15] hypothesized that the increased Doppler signal in TGDCs may be due to the presence of thyroid tissue in the cyst, which is not seen in DCs. Alternatively, some authors have suggested that the internal septae in TGDCs are associated with infection [20], even though some non-infected TGDC show internal septae and some infected TGDCs do not.

The results of our study are similar to the report by Oyewumi et al. [15] in that TGDCs tended to have ill-defined margins, heterogeneous internal echogenicity, and a close relationship with the hyoid bone. In addition to this, our study identified several additional helpful features, such as internal echogenic dots and multilocularity. We speculate that echogenic dots over the hypoechoic background in DCs could be due to reflections from cholesterol granules and the interface between coalesced fat lobules over the cheesy keratinaceous material and the fluid matrix [5]. We also suggest that multilocularity can sometimes occur if two or more portions of the TGD along the embryogenic course persist and give rise to cystic lesions, although TGDCs are usually unilocular [5].

To conclude, using US, TGDCs sometimes present as cystic lesions with an irregular shape, an ill-defined margin, or heterogeneous internal echogenicity. Furthermore, they tend to abut the hyoid bone, to show longitudinal extension into the tongue base, to display multilocularity, and to be located intramuscularly. On the contrary, DCs are round or oval in shape, well-defined, and tend to be homogeneously hypoechoic with echogenic dots, and to be located away from the hyoid bone in the subcutaneous layer.

ORCID: Hyoung In Choi: http://orcid.org/0000-0002-6784-3913; Young Hun Choi: http://orcid.org/0000-0002-1842-9062; Jung-Eun Cheon: http://orcid.org/00000003-1479-2064; Woo Sun Kim: http://orcid.org/0000-0003-2184-1311; In-One Kim: http://orcid.org/0000-0001-5800-3536

\section{Conflict of Interest}

No potential conflict of interest relevant to this article was reported.

\section{References}

1. Solomon JR, Rangecroft L. Thyroglossal-duct lesions in childhood. J Pediatr Surg 1984;19:555-561.

2. Santiago W, Rybak LP, Bass RM. Thyroglossal duct cyst of the tongue. J Otolaryngol 1985;14:261-264.

3. Telander RL, Filston HC. Review of head and neck lesions in infancy and childhood. Surg Clin North Am 1992;72:1429-1447.

4. Wadsworth DT, Siegel MJ. Thyroglossal duct cysts: variability of sonographic findings. AJR Am J Roentgenol 1994;163:1475-1477.

5. Koeller KK, Alamo L, Adair CF, Smirniotopoulos JG. Congenital cystic masses of the neck: radiologic-pathologic correlation. Radiographics 1999;19:121-146.

6. Taylor BW, Erich JB, Dockerty MB. Dermoids of the head and neck. Minn Med 1966;49:1535-1540.

7. Pryor SG, Lewis JE, Weaver AL, Orvidas LJ. Pediatric dermoid cysts of the head and neck. Otolaryngol Head Neck Surg 2005;132:938942.

8. Righini CA, Hitter A, Reyt E, Atallah I. Thyroglossal duct surgery: Sistrunk procedure. Eur Ann Otorhinolaryngol Head Neck Dis 2016;133:133-136.

9. Sistrunk WE. The surgical treatment of cysts of the thyroglossal tract. Ann Surg 1920;71:121-122.

10. Foley DS, Fallat ME. Thyroglossal duct and other congenital midline cervical anomalies. Semin Pediatr Surg 2006;15:70-75.

11. Stern JS, Ginat DT, Nicholas JL, Ryan ME. Imaging of pediatric head and neck masses. Otolaryngol Clin North Am 2015;48:225-246.

12. Gupta P, Maddalozzo J. Preoperative sonography in presumed thyroglossal duct cysts. Arch Otolaryngol Head Neck Surg 2001;127:200-202.

13. Vazquez E, Enriquez G, Castellote A, Lucaya J, Creixell S, Aso $C$, et al. US, CT, and MR imaging of neck lesions in children. Radiographics 1995;15:105-122.

14. Koch BL. Cystic malformations of the neck in children. Pediatr Radiol 2005:35:463-477.

15. Oyewumi M, Inarejos E, Greer ML, Hassouneh B, Campisi P, Forte $V$, et al. Ultrasound to differentiate thyroglossal duct cysts and dermoid cysts in children. Laryngoscope 2015;125:998-1003.

16. Policeni BA, Smoker WR, Reede DL. Anatomy and embryology of the thyroid and parathyroid glands. Semin Ultrasound CT MR 2012;33:104-114.

17. Gowda D, Joseph S. Thyroglossal cyst. Clin Pediatr (Phila) 2017 Jan 1 [Epub]. https://doi.org/10.1177/0009922816687330.

18. McAvoy JM, Zuckerbraun L. Dermoid cysts of the head and neck in children. Arch Otolaryngol 1976;102:529-531.

19. Ege G, Akman H, Senvar A, Kuzucu K. Case report: sublingual dermoid cyst. Tani Girisim Radyol 2003;9:57-59.

20. Kutuya N, Kurosaki Y. Sonographic assessment of thyroglossal duct cysts in children. J Ultrasound Med 2008;27:1211-1219. 
21. Sidell DR, Shapiro NL. Diagnostic accuracy of ultrasonography for midline neck masses in children. Otolaryngol Head Neck Surg 2011;144:431-434.

22. Gaddikeri S, Vattoth S, Gaddikeri RS, Stuart R, Harrison K, Young $D$, et al. Congenital cystic neck masses: embryology and imaging appearances, with clinicopathological correlation. Curr Probl Diagn Radiol 2014;43:55-67.

23. deMello DE, Lima JA, Liapis H. Midline cervical cysts in children: thyroglossal anomalies. Arch Otolaryngol Head Neck Surg 1987;113:418-420. 